\title{
GMR
}

\section{Increased survivin expression and its association with clinical parameters of congenital choledochal cysts}

\author{
Z.G. Wu ${ }^{1,2}$, G.X. Li ${ }^{1}$, B. Wang ${ }^{2}$, Z.M. Chen ${ }^{2}$ and Q. Feng ${ }^{2}$ \\ ${ }^{1}$ Department of General Surgery, Nanfang Hospital, Southern Medical University, \\ Guangzhou, China \\ ${ }^{2}$ Department of General Surgery, Shenzhen Children's Hospital, Shenzhen, China \\ Corresponding authors: G.X. Li / B. Wang \\ E-mail: snangxl@sina.com / szwb1967@126.com
}

Genet. Mol. Res. 15 (2): gmr.15028032

Received November 9, 2015

Accepted January 15, 2016

Published June 21, 2016

DOI http://dx.doi.org/10.4238/gmr.15028032

\begin{abstract}
The aim of the current study was to investigate survivin expression in congenital choledochal cysts (CCCs), and its associations with clinical parameters of CCCs. In total, 121 children with CCCs were included in this study as the case group, and their cysts were staged according to the Todani classification system. Additionally, 49 normal gallbladder specimens from healthy children were included as the control group. Survivin detection was conducted using immunohistochemical staining. Associations between positive survivin expression and clinical parameters of CCCs were then analyzed. Positive survivin expression was observed in the cytoplasm, and was seen as granular with yellow or dark brown staining. In the case group, positive survivin expression was detected in most tissues. Specifically, compared to that of normal tissues, the cystic-shaped and fusiform-shaped CCC tissues had significantly higher positive survivin expression rates (all $\mathrm{P}<0.05$ ). Importantly, positive survivin expression was also shown to be significantly associated with gender and histological type (both $\mathrm{P}<$
\end{abstract}


0.05). In conclusion, increased survivin expression was observed in CCC tissues, and was correlated with certain clinical parameters of CCCs, suggesting a possible prognostic value of survivin for CCC progression.

Key words: Congenital choledochal cysts; Protein expression; Survivin

\section{INTRODUCTION}

Congenital choledochal cysts (CCCs) are rare anomalies of the biliary tree found in the pediatric population that are characterized by either congenital cystic dilation of the extrahepatic or intrahepatic biliary ducts, and which are often associated with an anomalous junction of the pancreaticobiliary tracts (Liu et al., 2013). The prevalence of CCCs is generally higher among Asian populations than in the European and United States populations. Moreover, the incidence of CCCs among females is significantly higher than that among males, and accounts for 60 to $80 \%$ of the total incidence (Hung et al., 2011). Based on the Todani classification system first described in 1997, type I is the most common type of CCC, accounting for approximately $90 \%$ of all CCC cases (Todani et al., 2003). Although many theories have been put forth, the etiology of CCCs remains disputed and unclear, although most researchers insist that this disease is related to congenital pancreaticobiliary malformation and obstruction of the common bile duct (Liu et al., 2014). Additionally, bile duct dysplasia and viral infection may increase the risk of developing CCCs (Rauschenfels et al., 2009; Ohashi et al., 2013). Early diagnosis and appropriate treatment of CCCs are important, as these cysts are associated with a risk of carcinogenesis, and this risk increases with age. Although surgical treatments have significantly improved the survival outcomes of CCC patients, the long-term postoperative rate of complications such as cystolithiasis, cholangitis, acute pancreatitis, hepatolithiasis, and malignancies remains high (Gadelhak et al., 2014). Therefore, early recognition and proper management of CCCs are a focus of the current research.

Survivin is a member of the inhibitor of apoptosis protein (IAP) family, and is involved in the inhibition of apoptosis and regulation of cell division (Mita et al., 2008). Various clinical and experimental studies have shown that increased expression of survivin plays an important role in the development and progression of malignant neoplasms by reducing tumor cell apoptosis (Kim and McNiff, 2008; Mahalingam et al., 2010). This makes survivin a primary chemotherapeutic target, and a biomarker for the development and prognosis of various malignancies (Church and Talbot, 2012), including gastric (Bertazza et al., 2009), colorectal (Rödel et al., 2008), and bladder cancers (Margulis et al., 2008). As a multi-functional protein involved in inhibiting apoptosis, regulating cell division, and promoting angiogenesis, survivin can be expressed at significantly different levels in normal and malignant cells, where extremely low or absent expression levels have been observed in normal tissues, whereas elevated levels have been observed in various solid tumors ( $\mathrm{Li}$ and Ling, 2006; Mishra et al., 2015). To date, few studies have reported on the relationship between survivin and the clinicopathological features of CCCs. Therefore, the aim of the current study was to investigate the associations between survivin expression and the clinical parameters of CCCs.

\section{MATERIAL AND METHODS}

\section{Ethics statement}

This case-control study was approved by Shenzhen Children's Hospital. Written 
informed consent was obtained from the legal guardians of all enrolled pediatric subjects, and the study conformed to the guidelines and principles of the Declaration of Helsinki (General Assembly of the World Medical Association, 2014).

\section{Subjects}

One hundred and twenty-one children with CCCs who were treated at Shenzhen Children's Hospital from January 2010 to January 2014 were enrolled in this study as the case group. All patients were pathologically diagnosed with CCCs and the diagnoses were confirmed by surgery, with complete pathological and clinical data obtained for all patients. Additionally, all included patients had no other systemic diseases nor were their cases complicated by tumors. The study population consisted of 50 males and 71 females with a mean age of $5.44 \pm 4.10$ years. The cysts of all included CCC patients were staged according to the Todani classification system as follows: stage I, $\mathrm{N}=111$; stage III, $\mathrm{N}=2$, and stage IV, $\mathrm{N}$ $=8$ (Todani et al., 2003). Additionally, 49 normal gallbladder specimens from healthy children were obtained as the control group. This normal control group was examined by abdominal B ultrasound or CT for the exclusion of liver and gallbladder diseases, and all included normal tissues were confirmed by histopathologic examination.

\section{Immunohistochemistry (IHC)}

All collected specimens were fixed in $10 \%$ neutral buffered formalin, dehydrated through an ethanol gradient $(30,50,70,80,95$, and $100 \%$ ethanol), hyalinized in xylene, and embedded in conventional liquid paraffin for immunohistochemical staining. The paraffinembedded specimens were sectioned into four consecutive $5 \mu \mathrm{m}$-thick slices. All standard IHC reagents were provided by the Immunohistochemistry Laboratory of the Department of Pathology, Tongji Medical College, China. The primary mouse anti-human survivin monoclonal antibody was purchased from Wuhan Boster Biological Engineering Co., Ltd. (China). Known positive sections were used as a positive control, and phosphate-buffered saline (PBS) was substituted for the primary antibody as a negative control. After dewaxing and hydration, the paraffin sections were washed three times for 3 min each in PBS, pH 7.4. Subsequently, $50 \mu \mathrm{L}$ ( 1 drop) peroxidase blocking solution was added onto each section to block the activity of endogenous peroxidases, followed by a 10-min incubation at room temperature. Following another three washes in PBS (3 min each), $50 \mu \mathrm{L}$ (1 drop) nonimmune animal serum was added onto each section, and then incubated for $10 \mathrm{~min}$ at room temperature. After removing the serum, $50 \mu \mathrm{L}$ (1 drop) primary anti-survivin antibody was added onto each section, followed by a 60 -min incubation at room temperature or overnight at $4{ }^{\circ} \mathrm{C}$. Then, the sections were washed three times in PBS (5 min each). After removing the PBS, $50 \mu \mathrm{L}$ (1 drop) biotin-labeled secondary antibody (goat anti-mouse IgG, purchased from Southern Biotechnology Associates, Birmingham, AL, USA) was added onto each section, and then incubated at room temperature for $30 \mathrm{~min}$. Following another three washes in PBS (3 min each), the PBS was removed, and $50 \mu \mathrm{L}$ (1 drop) streptavidin-biotin-peroxidase solution was added onto each section, and the specimens were incubated at room temperature for 10 min. The sections were then washed three times with PBS ( 3 min each), then washed under tap water, slightly counterstained with hematoxylin, decomposed by $0.1 \% \mathrm{HCl}$, rinsed with $0.1 \%$ ammonia or PBS, and then converted to blue. The sections were then colored with the 
StreptABComplex/DAB Kit (Lab Vision Corporation, Fremont, CA, USA) in accordance with manufacturer protocols. Finally, the sections were dehydrated and dried through an ethanol gradient (as mentioned above), hyalinized in xylene, and sealed with neutral gum.

\section{Immunohistochemical analysis}

Positive expression of survivin was mainly observed in the nucleus/cytoplasm, and was visualized as yellowish-brown or yellow granular staining. In contrast, $\leq 5 \%$ cells exhibited brown particles in the cytoplasm, which were interpreted as survivin-negative under normal light microscopy. The slides were observed using a Nikon Eclipse E600 light microscope (Tokyo, Japan), and the positively labeled cells were counted in five randomly selected fields and expressed as the percentage of total cells. Each specimen was scored based on the percentage of positive cells $(<1 \%$ : 0 points; $1-25 \%$ : 1 point; $25-50 \%$ : 2 points; $51-$ 75\%: 3 points; and $>75 \%$ : 4 points) and staining intensity (colorless: 0 points; light yellow: 1 point; brownish-yellow: 2 points; and dark yellow: 3 points). The final scoring was determined according to the product of the two scores, with 0 points defined as negative (-), 1-2 points as positive $(++)$, and $>2$ points as strongly positive $(+++)$. Determination was conducted under double-blind conditions.

\section{Statistical analysis}

The SPSS 17.0 software (SPSS Inc., Chicago, IL, USA) was used for all data analyses. $\chi^{2}$ and Spearman rank correlation tests were performed for correlation analyses. P values $<0.05$ indicated significant differences.

\section{RESULTS}

\section{Clinicopathological characteristics}

Of the $121 \mathrm{CCC}$ patients aged 1 month to 15 years old (mean age of $5.44 \pm 4.10$ years), 50 were males and 71 were females. Of these CCC cases, 67 were cystic type and 54 were fusiform type. The CCC patients were further categorized into stage I $(\mathrm{N}=111)$, stage III (N $=2)$, and stage IV $(\mathrm{N}=8)$ based on the Todani classification system. Furthermore, there were 81 cases with combined bile duct, 15 cases with stenosis of the left hepatic duct, 11 cases with stenosis of the right hepatic duct, 8 cases of stenoses of both the right and left hepatic ducts, as well as 6 cases of stenosis of the common hepatic duct. The current study also included 49 healthy children aged 4 months to 11 years old (mean age of $4.84 \pm 3.87$ years) as the control group, which consisted of 16 males and 33 females. There were no significantly differences regarding age or gender between the case and control groups (both $\mathrm{P}>0.05$ ).

\section{Evaluation of survivin protein expression by IHC}

As shown in Figure 1, the cytoplasm showed a high expression of survivin as seen as positive staining, which presented in granular form, with yellow or dark brown color, whereas the nuclei were hardly stained. Sixteen of 49 normal tissues $(32.65 \%)$ in the control group stained positive for survivin (Table 1). In contrast, most of the tissues in the case group stained 
positive for survivin conferring survivin expression, including 56 of the 67 cystic-shaped tissues $(83.58 \%)$ and 32 of the 54 fusiform-shaped tissues $(59.26 \%)$, and these survivingpositive rates were found to be significantly higher than that of normal tissues (both $\mathrm{P}<0.05$ ).
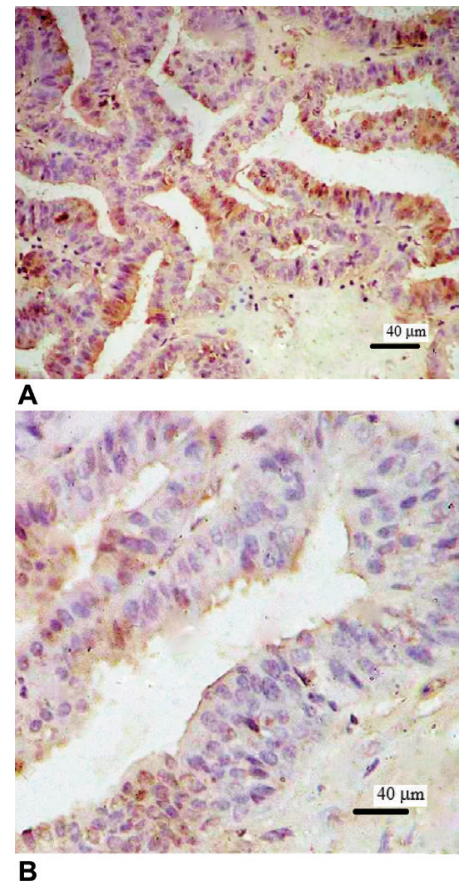

Figure 1. Immunohistochemical staining results for the protein expression of survivin. The cytoplasm showed high survivin expression, which presented as granular form, with yellow or dark brown staining, while the nuclei were hardly stained (A. cytoplasm, 200X; B. nuclei, 400X).

Table 1. Expression of survivin in cystic-shaped and fusiform-shaped tissues of congenital choledochal cyst patients, and in normal tissues from healthy children.

\begin{tabular}{l|c|c|c|c|c}
\hline & $\mathrm{N}$ & \multicolumn{3}{|c|}{ Survivin expression } & \multirow{2}{*}{ Positive rate (\%) } \\
\hline & & - & + & ++ & \\
\hline Normal tissues & 49 & 33 & 16 & 0 & 32.65 \\
\hline Cystic-shaped tissues & 67 & 11 & 25 & 31 & 83.58 \\
\hline Fusiform-shaped tissues & 54 & 22 & 19 & 13 & 59.26 \\
\hline
\end{tabular}

In the comparison of the cytoplasm of normal tissues with the cystic-shaped and fusiform-shaped tissues, $\mathrm{P}<0.05$.

\section{Associations between survivin expression and clinicopathologic parameters of CCCs}

As shown in Table 2, survivin expression was not markedly correlated to age, Todani stage, or diseases sub-type (all P $>0.05$ ). On the other hand, survivin expression was found to be statistically correlated with sex and histological type. Specifically, there were significantly higher positive survivin expression rates in female patients and patients with cystic-shaped CCCs than those of male patients and patients with fusiform-shaped CCCs, respectively (both $\mathrm{P}<0.05$ ). 
Table 2. Associations between survivin expression and clinical pathologic parameters of congenital choledochal cysts.

\begin{tabular}{|c|c|c|c|c|c|}
\hline \multirow[t]{2}{*}{ Parameters } & \multirow[t]{2}{*}{ Cases } & \multicolumn{2}{|c|}{ Positive expression of survivin } & \multirow[t]{2}{*}{$\chi^{2}$} & \multirow[t]{2}{*}{$\mathrm{P}$ value } \\
\hline & & Positive (\%) & Negative $(\%)$ & & \\
\hline \multicolumn{6}{|l|}{ Gender } \\
\hline Male & 50 & $30(60.00)$ & $20(40.00)$ & \multirow[t]{2}{*}{6.959} & \multirow[t]{2}{*}{0.008} \\
\hline Female & 71 & $58(81.69)$ & $13(18.31)$ & & \\
\hline \multicolumn{6}{|l|}{ Age } \\
\hline$\leq 5$ years & 78 & $55(70.51)$ & $23(29.49)$ & \multirow[t]{2}{*}{0.543} & \multirow[t]{2}{*}{0.461} \\
\hline$>5$ years & 43 & $33(76.74)$ & $10(23.26)$ & & \\
\hline \multicolumn{6}{|l|}{ Histological type } \\
\hline Cystic-shaped & 67 & $56(83.58)$ & $11(16.42)$ & \multirow[t]{2}{*}{5.755} & \multirow[t]{2}{*}{0.016} \\
\hline Fusiform-shaped & 54 & $32(59.26)$ & $22(40.74)$ & & \\
\hline \multicolumn{6}{|l|}{ Todani stage } \\
\hline Stage I & 111 & $78(70.27)$ & $33(29.73)$ & \multirow[t]{2}{*}{2.726} & \multirow[t]{2}{*}{0.099} \\
\hline Stages III + IV & 10 & $10(100.00)$ & $0(0.00)$ & & \\
\hline \multicolumn{6}{|l|}{ Diseases sub-types } \\
\hline Combined bile duct & 81 & $63(77.78)$ & $18(22.22)$ & \multirow[t]{5}{*}{5.055} & \multirow[t]{5}{*}{0.271} \\
\hline Stenosis of the left hepatic duct & 15 & $9(60.00)$ & $6(40.00)$ & & \\
\hline Stenosis of the right hepatic duct & 11 & $6(54.55)$ & $5(45.45)$ & & \\
\hline Stenoses of the right and left hepatic ducts & 8 & $5(62.50)$ & $3(37.50)$ & & \\
\hline Stenosis of the common hepatic duct & 6 & $5(83.33)$ & $1(16.67)$ & & \\
\hline
\end{tabular}

\section{DISCUSSION}

The aims of the current study were to investigate associations between survivin expression and clinical parameters of CCCs, and to explore the relationship of survivin expression and CCC progression. According to our observations, survivin was positively expressed in nearly twice as many cystic-shaped and fusiform-shaped tissues compared with that in normal tissues, indicating that the upregulation of survivin may occur in the early stages of CCC development. The deregulation of apoptosis has emerged as a hallmark of human malignancies and carcinogenesis (Fuhrman et al., 1982; Wang et al., 2013; Uchida et al., 2013). In this regard, the IHC results of this study showed that there was a significantly higher positive expression rate of survivin in CCC tissues than that in normal tissues, which in turn provides evidence of the occurrence of apoptosis deregulation in CCC tissues, and strengthens the case for survivin to predict the existence of deregulated apoptosis. Survivin exhibits many biological effects, including multiple anti-apoptotic functions, which are mainly attributable to its differential subcellular localization, phosphorylation, and acetylation (Tyner et al., 2012; Chang et al., 2013). Although belonging to the IAP family, survivin is prominently expressed in the vast majority of neoplasms and not in normal differentiated tissue, unlike other IAP members (Brustmann et al., 2011). Through survivin detection, several previous studies have shown that the selective expression of this protein in malignant tissues makes it an attractive therapeutic target for different malignancies (Fukuda and Pelus, 2006; Vandghanooni et al., 2011). From a biological standpoint, survivin suppresses apoptosis, regulates cell division, and promotes angiogenesis (Mita et al., 2008). For example, Margulis et al. (2008) demonstrated that inhibition of survivin expression impedes tumor cell proliferation and promotes spontaneous or chemotherapy-induced apoptosis in a pre-clinical bladder tumor model. Additionally, Liu et al. (2011) found that gallbladder cancer, which is characterized by rapid progress, poor prognosis, and aberrantly high survivin expression, was inhibited by survivin promoter-regulated oncolytic adenovirus carrying the $P 53$ gene. These 
aforementioned studies, in addition to the results herein, suggest that detection of survivin may have a diagnostic/prognostic value for CCCs. Importantly, there was an evident difference in survivin expression between the cystic-shaped and fusiform-shaped tissues, where higher survivin expression was found in the former. A possible explanation for these observations may be that the apoptotic rate of epithelial cells has been shown to be positively correlated with the degree of duct damage, highlighting the essential role of cell apoptosis and relevant markers thereof in the progression of this disease. Cystic-shaped CCCs are characterized by relatively large sizes and thick cyst walls, with moderate to large numbers of elastic and reticular fibers (Ahanatha Pillai et al., 2012). In contrast, fusiform-shaped CCCs are relatively smaller and have thinner walls without elastic or reticular fibers (De and Basu, 2007). Survivin expression may therefore be different between cystic-shaped and fusiform-shaped CCCs due to their structural differences. Additionally, the results of this study demonstrated that positive survivin expression was significantly higher in female CCC patients than that in males. Since CCCs have a high rate of carcinogenesis, the identification of useful early detection biomarkers would be important for the diagnosis and treatment of this disease. Epidemiological investigation has found that CCCs have a relatively higher incidence in females than in males (Shanmugam et al., 2005), which in turn may explain why survivin expression levels were observed to be higher in females herein.

In the current study, we did not investigate the signaling pathways of survivin in $\mathrm{CCCs}$, and thus our data do not provide any mechanistic explanations for our observations. Another limitation of our study lies in the relatively small sample size, which may have affected our results. Additionally, our study measured survivin in vitro, which may also have biased our results. Therefore, future efforts should focus on the mechanistic role of survivin and its complex interactions with other clinical biomarkers in CCCs, include lager sample sizes, and measure survivin both in vivo and in vitro.

In conclusion, we provide strong evidence that survivin is positively expressed in CCC tissues, and may be correlated with clinicopathological features of CCCs. The results of the current study could be enhanced by further studies and effective meta-analyses of the cumulative results, which may lead to better diagnostics, prognostics, and treatments for CCCs in the future. Therefore, additional efforts are needed to provide more powerful insights on this topic.

\title{
Conflicts of interest
}

The authors declare no conflict of interest.

\section{ACKNOWLEDGMENTS}

We would like to acknowledge the researcher in Nanfang Hospital, Southern Medical University and Shenzhen Children's Hospital for their helpful advice on this study.

\section{REFERENCES}

\begin{abstract}
Ahanatha Pillai S, Velayutham V, Perumal S, Ulagendra Perumal S, et al. (2012). Biliary cystadenomas: a case for complete resection. HPB Surg. 2012: 501705. http://dx.doi.org/10.1155/2012/501705

Bertazza L, Mocellin S, Marchet A, Pilati P, et al. (2009). Survivin gene levels in the peripheral blood of patients with gastric cancer independently predict survival. J. Transl. Med. 7: 111. http://dx.doi.org/10.1186/1479-5876-7-111

Brustmann H, Hinterholzer S and Brunner A (2011). immunohistochemical expression of survivin and g-H2AX in vulvar intraepithelial neoplasia and low-stage squamous cell carcinoma. Int. J. Gynecol. Pathol. 30: 583-590. http://dx.doi. org/10.1097/PGP.0b013e31821e18fd
\end{abstract}


Chang CH, Huang CC, Tsai FY, Lee JY, et al. (2013). Survivin - biology and potential as a therapeutic target in oncology. Onco Targets Ther. 6: 1453-1462. http://dx.doi.org/10.2147/OTT.S33374

Church DN and Talbot DC (2012). Survivin in solid tumors: rationale for development of inhibitors. Curr. Oncol. Rep. 14: 120-128. http://dx.doi.org/10.1007/s11912-012-0215-2

De U and Basu M (2007). Hydatid cyst of common bile duct mimicking type 1 choledochal cyst. J. Indian Assoc. Pediatr. Surg. 12: 83-84. http://dx.doi.org/10.4103/0971-9261.33229

Fuhrman SA, Lasky LC and Limas C (1982). Prognostic significance of morphologic parameters in renal cell carcinoma. Am. J. Surg. Pathol. 6: 655-664.http://dx.doi.org/10.1097/00000478-198210000-00007

Fukuda S and Pelus LM (2006). Survivin, a cancer target with an emerging role in normal adult tissues. Mol. Cancer Ther. 5: 1087-1098.http://dx.doi.org/10.1158/1535-7163.MCT-05-0375

Gadelhak N, Shehta A and Hamed H (2014). Diagnosis and management of choledochal cyst: 20 years of single center experience. World J. Gastroenterol. 20: 7061-7066.http://dx.doi.org/10.3748/wjg.v20.i22.7061

General Assembly of the World Medical Association (2014). World Medical Association Declaration of Helsinki: ethical principles for medical research involving human subjects. J. Am. Coll. Dent. 81: 14-18.

Hung MH, Lin LH, Chen DF and Huang CS (2011). Choledochal cysts in infants and children: experiences over a 20-year period at a single institution. Eur. J. Pediatr. 170: 1179-1185.http://dx.doi.org/10.1007/s00431-011-1429-2

Kim J and McNiff JM (2008). Nuclear expression of survivin portends a poor prognosis in Merkel cell carcinoma. Mod. Pathol. 21: 764-769. http://dx.doi.org/10.1038/modpathol.2008.61

Li F and Ling X (2006). Survivin study: an update of "what is the next wave"? J. Cell. Physiol. 208: 476-486.http://dx.doi. org/10.1002/jcp. 20634

Liu C, Sun B, An N, Tan W, et al. (2011). Inhibitory effect of Survivin promoter-regulated oncolytic adenovirus carrying P53 gene against gallbladder cancer. Mol. Oncol. 5: 545-554. http://dx.doi.org/10.1016/j.molonc.2011.10.001

Liu Y, Liu B, Zhou Y, Wang Y, et al. (2013). Treatment of long-term complications after primary surgery for congenital choledochal cysts. Am. Surg. 79: 1221-1224.

Liu Y, Yao X, Li S, Liu W, et al. (2014). Comparison of therapeutic effects of laparoscopic and open operation for congenital choledochal cysts in adults. Gastroenterol. Res. Pract. 2014: 670260. http://dx.doi.org/10.1155/2014/670260

Mahalingam D, Medina EC, Esquivel JA, 2nd, Espitia CM, et al. (2010). Vorinostat enhances the activity of temsirolimus in renal cell carcinoma through suppression of survivin levels. Clin. Cancer Res. 16: 141-153. http://dx.doi. org/10.1158/1078-0432.CCR-09-1385

Margulis V, Lotan Y and Shariat SF (2008). Survivin: a promising biomarker for detection and prognosis of bladder cancer. World J. Urol. 26: 59-65. http://dx.doi.org/10.1007/s00345-007-0219-y

Mishra R, Palve V, Kannan S, Pawar S, et al. (2015). High expression of survivin and its splice variants survivin DEx3 and survivin 2 B in oral cancers. Oral Surg. Oral Med. Oral Pathol. Oral Radiol. 120: 497-507. http://dx.doi. org/10.1016/j.oooo.2015.06.027

Mita AC, Mita MM, Nawrocki ST and Giles FJ (2008). Survivin: key regulator of mitosis and apoptosis and novel target for cancer therapeutics. Clin. Cancer Res. 14: 5000-5005. http://dx.doi.org/10.1158/1078-0432.CCR-08-0746

Ohashi T, Wakai T, Kubota M, Matsuda Y, et al. (2013). Risk of subsequent biliary malignancy in patients undergoing cyst excision for congenital choledochal cysts. J. Gastroenterol. Hepatol. 28: 243-247. http://dx.doi.org/10.1111/j.14401746.2012.07260.x

Rauschenfels S, Krassmann M, Al-Masri AN, Verhagen W, et al. (2009). Incidence of hepatotropic viruses in biliary atresia. Eur. J. Pediatr. 168: 469-476. http://dx.doi.org/10.1007/s00431-008-0774-2

Rödel F, Frey B, Leitmann W, Capalbo G, et al. (2008). Survivin antisense oligonucleotides effectively radiosensitize colorectal cancer cells in both tissue culture and murine xenograft models. Int. J. Radiat. Oncol. Biol. Phys. 71: 247255.http://dx.doi.org/10.1016/j.ijrobp.2008.02.011

Shanmugam V, Beattie GC, Yule SR, Reid W, et al. (2005). Is magnetic resonance cholangiopancreatography the new gold standard in biliary imaging? Br. J. Radiol. 78: 888-893. http://dx.doi.org/10.1259/bjr/51075444

Todani T, Watanabe Y, Toki A and Morotomi Y (2003). Classification of congenital biliary cystic disease: special reference to type Ic and IVA cysts with primary ductal stricture. J. Hepatobiliary Pancreat. Surg. 10: 340-344. http://dx.doi. org/10.1007/s00534-002-0733-7

Tyner JW, Jemal AM, Thayer M, Druker BJ, et al. (2012). Targeting survivin and p53 in pediatric acute lymphoblastic leukemia. Leukemia 26: 623-632. http://dx.doi.org/10.1038/leu.2011.249

Uchida Y, Chiyomaru T, Enokida H, Kawakami K, et al. (2013). MiR-133a induces apoptosis through direct regulation of GSTP1 in bladder cancer cell lines. Urol. Oncol. 31: 115-123. http://dx.doi.org/10.1016/j.urolonc.2010.09.017

Vandghanooni S, Eskandani M, Montazeri V, Halimi M, et al. (2011). Survivin-deltaEx3: a novel biomarker for diagnosis of papillary thyroid carcinoma. J. Cancer Res. Ther. 7: 325-330. http://dx.doi.org/10.4103/0973-1482.87038

Wang WZ, Li L, Liu MY, Jin XB, et al. (2013). Curcumin induces FasL-related apoptosis through p38 activation in human hepatocellular carcinoma Huh7 cells. Life Sci. 92: 352-358. http://dx.doi.org/10.1016/j.lfs.2013.01.013 